\title{
The anxiolytic effects of resistance exercise
}

\author{
Justin C. Strickland and Mark A. Smith* \\ Department of Psychology and Program in Neuroscience, Davidson College, Davidson, NC, USA
}

Edited by:

James H. Cauraugh, University of

Florida, USA

\section{Reviewed by:}

Marco Taubert, Max-Planck-Institute for Human Cognitive and Brain Sciences, Germany

Craig R. Hall, University of Western Ontario, Canada

\section{${ }^{*}$ Correspondence:}

Mark A. Smith, Department of Psychology and Program in Neuroscience, Davidson College, Davidson, NC 28035-7037, USA e-mail: masmith@davidson.edu
Numerous studies have revealed the beneficial effects of regular exercise across a variety of mental health measures. Although a great deal of attention has been paid to the role of aerobic exercise, less is known about the role of resistance exercise (i.e., strength training) in mental health outcomes. Resistance exercise includes a broad group of procedures that evoke repeated muscle action against resistances above those encountered in daily life. A growing body of literature has identified anxiolytic effects of resistance exercise in human populations after both single-bout sessions and long-term training. This research has shown that resistance training at a low-to-moderate intensity ( $<70 \% 1$ repetition maximum) produces the most reliable and robust decreases in anxiety. Importantly, anxiolytic effects have been observed across a diverse range of populations and dependent measures. These findings provide support for the use of resistance exercise in the clinical management of anxiety.

Keywords: anxiety, exercise, mental health, resistance, strength training
Numerous studies have revealed a relationship between regular exercise and improvements in mental health, including increased cognition, mood, and general quality of life (Penedo and Dahn, 2005; Puetz et al., 2006). Although much of this research has examined the effects of aerobic exercise on mental health outcomes, resistance exercise (i.e., strength training) also produces many physiological and psychological benefits. In the only review of resistance exercise and mental health, increases in cognition, increases in self-esteem, and decreases in depression were noted across several randomized clinical trials (O'Connor et al., 2010). In addition to these effects, a growing body of evidence indicates that resistance exercise produces anxiolytic effects across a range of dependent measures, experimental procedures, and participant populations.

\section{RESISTANCE EXERCISE PROCEDURES}

Resistance exercises include a variety of procedures that evoke repeated muscle action against resistances above those encountered in daily activities (Physical Activity Guidelines Advisory Committee, 2008). Resistance training usually requires the use of equipment, including elastic bands, free weights, or resistance machines, and it is performed in a series of sets that include a specific number of repetitions. A set of resistance exercise may involve combinations of concentric (i.e., shortening) or eccentric (i.e., lengthening) muscle movement with single- or multiple-joint action (American College of Sports Medicine, 2009). Resistance exercise intensity is usually measured as repetition maximums (RMs) with 1RM representing the maximal amount an individual can lift in a single repetition of a given exercise. Resistance training is more common in men than women, with $27 \%$ of males and $19 \%$ of females reporting regular resistance exercise (Schoenborn et al., 2013).

Numerous studies have documented the beneficial effects of resistance exercise on strength and performance-related outcomes, including increases in muscle mass, bone density, and endurance (e.g., see reviews by Crewther et al., 2006, 2011). This research also indicates that the benefits of resistance exercise extend beyond muscle and tissue growth and include alterations in neurobiological systems relevant to mental health and anxiety-related outcomes (e.g., cortisol and the HPA axis; Crewther et al., 2011). These studies are advancing our understanding of the role of resistance exercise in mental health by showing that resistance exercise produces robust alterations in the biological mediators of anxiety with potentially important implications for mental health outcomes.

\section{ROLE OF RESISTANCE EXERCISE IN ANXIETY MEASURING ANXIETY}

As a construct, anxiety has been defined in a variety of ways (Endler and Kocovski, 2001). In the context of resistance exercise research, a distinction is made between anxiety as a state and anxiety as a trait. State anxiety is an acute emotional condition characterized by physiological arousal and accompanying feelings of tension and apprehension; in contrast, trait anxiety is the predisposition to respond in this state-conditional manner (Spielberger, 1966). The State-Trait Anxiety Inventory (STAI) is a 20-item measure of state and trait anxiety, with demonstrated reliability and validity (Spielberger, 1983). Other popular measures of anxiety include the Profile of Mood States (POMS), Hospital Anxiety and Depression Scale (HADS), and Symptom Checklist-90-R (SCL-90-R), all of which measure state rather than trait anxiety.

\section{ANXIOLYTIC EFFECTS OF SINGLE-BOUT RESISTANCE EXERCISE}

The influence of a single session of resistance exercise on anxiety has been examined using both between-subjects and within-subjects designs, with most samples drawn from college populations and convenience groups (e.g., new enrollees in a weight-lifting course). Multiple studies have demonstrated the anxiolytic effects of single bouts of resistance exercise in human populations, and many of these studies have revealed a critical role for exercise intensity (see Table 1). Specifically, resistance 
Table 1 |The effects of single-bout resistance exercise on anxiety measures.

\begin{tabular}{|c|c|c|c|c|c|c|c|c|}
\hline Study & Sex & Age & $N$ & Design (sampling) & Intensity (1RM) & Minutes & Measure & Anxiety outcome \\
\hline $\begin{array}{l}\text { Bartholomew and Linder } \\
\text { (1998) }\end{array}$ & $\mathrm{M} / \mathrm{F}$ & 22 & 20 & Within (recruit) & $\begin{array}{l}\text { High }(75-85 \%) \text { vs low } \\
(40-50 \%)\end{array}$ & 20 & STAI & $\begin{array}{l}\text { High }=\text { increased and } \\
\text { low }=\text { decreased }\end{array}$ \\
\hline Bibeau et al. (2010) & $\mathrm{M} / \mathrm{F}$ & 20 & $18-24$ & Between (cluster) & $\begin{array}{l}\text { High }(80-85 \%) \text { vs low } \\
(50-55 \%)\end{array}$ & 30 & STAI & $\begin{array}{l}\text { Decreased (greatest with } \\
\text { low) }\end{array}$ \\
\hline Focht (2002) & $\mathrm{F}$ & 21 & 19 & Within (cluster) & $\begin{array}{l}\text { Self-selected vs fixed } \\
(75 \%)\end{array}$ & $30-45$ & STAI & Decreased \\
\hline Focht and Koltyn (1999) & $M / F$ & NA & 28 & Between (cluster) & 50 vs $80 \%$ & 30 & STAI & Decreased (only at $50 \%$ ) \\
\hline Focht and Koltyn (2009) & M & 21 & 21 & Within (recruit) & $75 \%$ & 45 & STAI & No change \\
\hline Garvin et al. (1997) & M & 22 & 15 & Between (recruit) & $70 \%$ & 50 & STAI & No change \\
\hline Koltyn etal. (1995) & $M / F$ & 19 & 25 & Between (cluster) & $\begin{array}{l}\text { Self-selected (30-80\% } \\
\text { BW) }\end{array}$ & 50 & STAI & No change \\
\hline $\begin{array}{l}\text { O'Connor and Cook } \\
\text { (1998) }\end{array}$ & $\mathrm{M} / \mathrm{F}$ & 25 & 11 & Within (cluster) & $10 \%$ & $30-45$ & STAI & Decreased \\
\hline Parker et al. (2011) & M & 23 & 18 & Within (recruit) & $70 \%$ & NA & POMS & No change \\
\hline Passos et al. (2010) & $M / F$ & 42 & 12 & Between (recruit) & $50 \%$ & 50 & STAI & No change \\
\hline Raglin et al. (1993) & $M / F$ & 20 & 26 & Within (recruit) & $70-80 \%$ & 30 & STAI & Increased \\
\hline
\end{tabular}

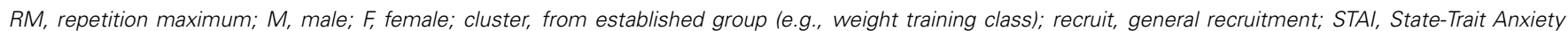
Inventory; POMS, Profile of Mood States; $N$, sample size in exercise group; age, mean age.

exercise training that includes high intensities (i.e., $>70 \% 1 \mathrm{RM}$ ) is less likely to produce decreases in state anxiety than training with moderate or low intensities (i.e., 50-70\% 1RM). Although significant decreases were not observed in many of the first studies to examine the effects of resistance exercise on state anxiety (Raglin et al., 1993; Koltyn et al., 1995; Garvin et al., 1997; Koltyn and Arbogast, 1998), all of those studies included resistance intensities at or above 70\% 1RM. When exercise intensity has been reduced to $40-55 \% 1 \mathrm{RM}$, acute decreases in state anxiety have been consistently reported (Bartholomew and Linder, 1998; Bibeau et al., 2010), and anxiolytic effects have been demonstrated at intensities as low as 10\% 1RM (O'Connor and Cook, 1998).

Studies in which exercise intensities are directly compared also indicate a critical role for low-to-moderate resistance intensities. For instance, a single bout of resistance exercise at 45\% 1RM produced decreases in state anxiety lasting until $120 \mathrm{~min}$ post-exercise, but the same effects were not observed at 30\% 1RM or $60 \% 1 \mathrm{RM}$ (O’Connor et al., 1993). Similarly, exercise procedures performed at $50 \% 1 \mathrm{RM}$ but not $80 \% 1 \mathrm{RM}$ were shown to produce decreases in state anxiety, and this effect was not dependent on a previous history of resistance training (Focht and Koltyn, 1999). The duration of rest intervals between sets may also play an important role in the anxiolytic effects of resistance exercise, given that exercise performed at low intensities with long rests between sets (i.e., 50-55\% $1 \mathrm{RM}$ and $90 \mathrm{~s}$ ) produced robust decreases in state anxiety relative to high intensities with short rests (i.e., 80-85\% 1RM and $30 \mathrm{~s}$;
Bibeau et al., 2010). In one study, anxiogenic effects were observed with resistance exercise in excess of 85\% 1RM, but anxiolytic effects were observed at intensities of 50\% 1RM (Bartholomew and Linder, 1998). It should be noted that a recent study conducted in middle-aged patients (30-55 years) with chronic primary insomnia failed to report a reduction in anxiety after a single bout of resistance exercise at 50\% 1RM (Passos et al., 2010). It is unclear if the effects reported in that study were a consequence of the patients' insomnia or their older age, given that few studies have examined acute bouts of resistance exercise in clinical populations or participants over 25 years of age. Regardless, most findings support the importance of low-to-moderate intensities when trying to maximize the anxiolytic effects of single-bouts of resistance exercise.

Gender may also play a role in the anxiolytic effects of resistance exercise, with females more sensitive to these effects than males. For instance, when given access to resistance exercise at either a self-selected intensity or a fixed intensity (75\% 1RM), women exhibited robust decreases in state anxiety (Focht, 2002). These effects are particularly compelling considering single-bout anxiolytic effects have not been reliably demonstrated in men exercising at intensities greater than 70\% 1RM (e.g., Garvin et al., 1997; Focht and Koltyn, 2009; Parker et al., 2011). Although some studies have failed to report sex differences (e.g., Bartholomew and Linder, 1998), the majority of findings suggest that females may be more sensitive to the anxiolytic effects of resistance exercise than males. 


\section{ANXIOLYTIC EFFECTS OF LONG-TERM RESISTANCE TRAINING}

In order to be effective in a clinical population, the acute anxiolytic effects of resistance exercise should persist during long-term resistance training. Many studies have examined the role of longterm resistance training in anxiety outcomes and several of these studies have been conducted in clinical populations (see Table 2). To date, long-term resistance training has been examined primarily with parallel-groups (i.e., between-subjects) designs that use simple randomization and traditional control groups (e.g., waiting list controls; Norvell and Belles, 1993; Jette et al., 1996; Herring et al., 2012). Additionally, several studies have included social interaction as a component of control conditions (e.g., attendance at fitness centers or social groups without the prescribed resistance training; Cassilhas et al., 2007, 2010) in order to help control for the influence of these potentially confounding factors.

Concordant with single-bout outcomes, the effects of resistance training on anxiety are moderated by exercise intensity, with the most robust decreases observed at low-to-moderate intensities. For instance, in a 24-week, community-based intervention, greater decreases in anxiety were observed in older participants (65-75 years) performing exercise at 50\% 1RM relative to those exercising at $80 \%$ 1RM (Cassilhas et al., 2007). These same effects were observed after a 12-week intervention, with low-to-moderate intensity exercise (55-65\% 1RM) producing greater decreases in anxiety than high intensities (75-85\% 1RM; Tsutsumi et al., 1997, 1998). In contrast, a work-place intervention using light resistance training (30\% 1RM) failed to reduce anxiety outcomes, suggesting that an intensity threshold might exist for the anxiolytic effects of resistance exercise (Sjogren et al., 2006). Together, these findings support the importance of low-tomoderate intensities in conferring anxiolytic effects after resistance training.

Several studies have examined the effects of resistance exercise on anxiety in older populations ( $>60$ years), with generally positive outcomes. Whether conducted in the laboratory (Cassilhas et al., 2007, 2010), community (Tsutsumi et al., 1997, 1998), or home (Jette et al., 1996), these studies indicate that participation in

Table 2 |The effects of long-term resistance exercise on anxiety measures.

\begin{tabular}{|c|c|c|c|c|c|c|c|c|c|c|c|}
\hline Study & Population & Sex & Age & $\boldsymbol{N}$ & $\begin{array}{l}\text { Design } \\
\text { (rand) }\end{array}$ & $\begin{array}{l}\text { Intensity } \\
\text { (1RM) }\end{array}$ & Weeks & Days & Minutes & Measure & $\begin{array}{l}\text { Anxiety } \\
\text { outcome }\end{array}$ \\
\hline Agil et al. (2010) & Postmenopausal & $\mathrm{F}$ & 53 & 18 & $\begin{array}{l}\text { Between } \\
\text { (simple) }\end{array}$ & $\mathrm{NI}$ & 8 & 3 & $\mathrm{NI}$ & SCL-90 & Decreased \\
\hline Aidar et al. (2012) & Ischemic stroke & $\mathrm{M} / \mathrm{F}$ & 52 & 11 & $\begin{array}{l}\text { Between } \\
\text { (simple) }\end{array}$ & Self-selected & 12 & 3 & $45-60$ & STAI & Decreased \\
\hline $\begin{array}{l}\text { Bircan et al. } \\
(2008)\end{array}$ & Fibromyalgia & $\mathrm{F}$ & 46 & 13 & $\begin{array}{l}\text { Between } \\
\text { (simple) }\end{array}$ & Progressive & 8 & 3 & 40 & HADS & $\begin{array}{l}\text { No change } \\
\text { (trend) }\end{array}$ \\
\hline $\begin{array}{l}\text { Cassilhas etal. } \\
(2007)\end{array}$ & Older (healthy) & $\mathrm{M} / \mathrm{F}$ & 68 & 20 & $\begin{array}{l}\text { Between } \\
\text { (simple) }\end{array}$ & $50 \%$ vs $80 \%$ & 24 & 3 & 60 & POMS & $\begin{array}{l}\text { Decreased (in } \\
50 \% \text { ) }\end{array}$ \\
\hline $\begin{array}{l}\text { Cassilhas etal., } \\
2010\end{array}$ & Older (healthy) & $M$ & 68 & 20 & $\begin{array}{l}\text { Between } \\
\text { (simple) }\end{array}$ & $80 \%$ & 24 & 3 & 60 & STAI & Decreased \\
\hline $\begin{array}{l}\text { Courneya et al., } \\
2007 a, b\end{array}$ & Breast cancer & $\mathrm{F}$ & 49 & 73 & $\begin{array}{l}\text { Between } \\
\text { (stratified) }\end{array}$ & $60-70 \%$ & 17 & 3 & $15-45$ & STAI & $\begin{array}{l}\text { No change } \\
\text { (trend) }\end{array}$ \\
\hline $\begin{array}{l}\text { Herring et al. } \\
(2012)\end{array}$ & GAD & $\mathrm{F}$ & 26 & 10 & $\begin{array}{l}\text { Between } \\
\text { (blocked) }\end{array}$ & $\begin{array}{l}35-50 \%+ \\
5 \% \text { weekly }\end{array}$ & 6 & 2 & 46 & PSWO & $\begin{array}{l}\text { Decreased (with } \\
\text { aerobic) }\end{array}$ \\
\hline Jette et al. (1996) & Older (healthy) & $\mathrm{M} / \mathrm{F}$ & 72 & 42 & $\begin{array}{l}\text { Between } \\
\text { (simple) }\end{array}$ & Progressive & $12-15$ & 2 & 30 & POMS & $\begin{array}{l}\text { Decreases } \\
\text { (greatest in M) }\end{array}$ \\
\hline $\begin{array}{l}\text { Norvell and } \\
\text { Belles (1993) }\end{array}$ & Law officers & $M$ & 33 & 14 & $\begin{array}{l}\text { Between } \\
\text { (simple) }\end{array}$ & Progressive & 16 & 3 & 20 & SCL-90 & Decreased \\
\hline $\begin{array}{l}\text { Sjogren et al. } \\
(2006)\end{array}$ & Office workers & $M / F$ & 46 & 90 & $\begin{array}{l}\text { Within } \\
\text { (cluster) }\end{array}$ & $30 \%$ & 15 & 5 & $6-8$ & VAS & No change \\
\hline $\begin{array}{l}\text { Tsutsumi et al. } \\
\text { (1997) }\end{array}$ & Older (healthy) & $\mathrm{M} / \mathrm{F}$ & 69 & 14 & $\begin{array}{l}\text { Between } \\
\text { (simple) }\end{array}$ & $\begin{array}{l}75-85 \% \text { vs } \\
55-65 \%\end{array}$ & 12 & 3 & $\mathrm{NI}$ & POMSSTAI & $\begin{array}{l}\text { Decreased } \\
\text { (greatest 55-65) }\end{array}$ \\
\hline $\begin{array}{l}\text { Tsutsumi et al. } \\
\text { (1998) }\end{array}$ & Older (healthy) & $\mathrm{M} / \mathrm{F}$ & 69 & 12 & $\begin{array}{l}\text { Between } \\
\text { (simple) }\end{array}$ & $\begin{array}{l}75-85 \% \text { vs } \\
55-65 \%\end{array}$ & 12 & 3 & $\mathrm{NI}$ & POMSSTAI & $\begin{array}{l}\text { Decreased } \\
\text { (greatest 55-65) }\end{array}$ \\
\hline
\end{tabular}

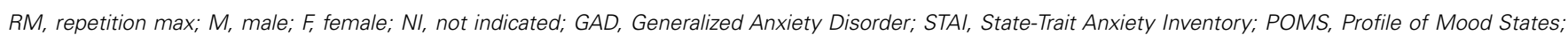

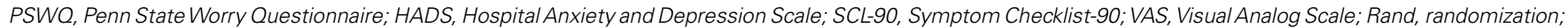
$N$, sample size in exercise group; age, mean. 
regular resistance exercise produces decreases in measures of state and trait anxiety in older populations. No study has compared the anxiolytic effects of resistance training across different age groups, although decreases have been observed in both middle-aged (mean age $=32.8$ years; Norvell and Belles, 1993) and post-menopausal (mean age $=52.6$ years; Agil et al., 2010) populations. Together, these findings indicate that resistance training decreases anxiety across age groups, and may be an effective intervention for older populations suffering from anxiety-related concerns.

A limited number of studies have been conducted in clinical populations with either primary anxiety or anxiety related to another condition. Randomized clinical trials in patients with fibromyalgia (Bircan et al., 2008) and patients with breast cancer undergoing chemotherapy (Courneya et al., 2007a,b) have revealed small but non-significant anxiolytic effects of resistance training. Significant anxiolytic effects were observed after resistance training during stroke rehabilitation (Aidar et al., 2012), which is consistent with the large body of literature supporting the use of resistance exercise for stroke patients (see review by Brogardh and Lexell, 2012). In the only study of primary anxiety symptoms, resistance exercise produced small but nonsignificant decreases in worry-related symptoms during a 6-week program in females with generalized anxiety disorder (Herring et al., 2012). When resistance training was combined with aerobic exercise, which alone failed to decrease anxiety symptoms, robust decreases in anxiety were observed. This effect suggests that resistance exercise may enhance the effects of other modes of exercise, or conversely, other modes of exercise may enhance the effects of resistance training. Although more data are needed regarding the effects of resistance training in clinical populations, these preliminary findings provide support for the feasibility and efficacy of resistance exercise in the treatment of anxiety as a primary and secondary symptom.

\section{FUTURE DIRECTIONS}

The studies reviewed reveal a putative role for resistance exercise in anxiety-related outcomes; however, more studies are needed examining these effects in clinical populations. With $22 \%$ of the population over 13 suffering from anxiety disorders in a given year, treating anxiety symptoms poses a great challenge for the mental health community (Kessler et al., 2012). Unfortunately, a paucity of research has examined the anxiolytic effects of single bouts of resistance exercise in groups other than young healthy adults, namely convenience samples drawn from college populations. Furthermore, studies of long-term resistance training have largely been conducted in healthy populations, with only one study examining the effects of resistance training in the treatment of primary anxiety disorders. Additional information regarding clinical populations would help guide the design and implementation of resistance exercise-based interventions.

Although resistance exercise has demonstrated anxiolytic effects, the mechanisms mediating these effects are less clear. Numerous studies have demonstrated alterations in hypothalamic pituitary adrenal (HPA) axis function related to anxiety-related disorders. Specifically, anxiety often occurs concurrently with unanticipated or extended activation of the stress response along the HPA axis, resulting in hypervigilance, fear, and sympathetic dysregulation (Chrousos, 2009). Consequently, anxiety disorders can be thought of as a disorder of the HPA axis in the form of hyperactivity (e.g., OCD, Panic Disorder, Generalized Anxiety Disorder; Chrousos, 2009) or hypoactivity (e.g., posttraumatic stress disorder; Meewisse et al., 2007). Through modulation of cortisol activity, resistance exercise may affect anxiety at the level of the HPA axis (Crewther et al., 2006, 2011). An understanding of an individual's response to stress and the associated changes along the HPA axis could give insight into the mechanisms mediating anxiety-related outcomes; however, in the context of resistance exercise, no study has examined cortisol and anxiety responses concurrently, making direct correlations between these outcomes impossible. Such studies would greatly aid our understanding of the biological mediators of the anxiolytic effects of resistance exercise.

Little is known about other central nervous system changes induced by resistance exercise and how these alterations might affect measures of anxiety and general mental health. The neurobiological effects of aerobic exercise have been well characterized, and it is thought that many of the positive outcomes on cognition and mental health are mediated through exercise-induced changes in brain-derived neurotrophic factor (BDNF) and monoamine neurotransmitters (Southwick et al., 2005; Hillman et al., 2009; Gomez-Pinilla and Hillman, 2013). The limited data describing the influence of resistance exercise on central nervous system activity indicate that its effects differ from aerobic exercise. For example, insulin-like growth factor 1 (IGF-1) is known to regulate learning and memory through hippocampal plasticity (Aberg et al., 2006), and IGF-1 is increased by resistance exercise in animals (Cassilhas et al., 2012) and humans (e.g., Cassilhas et al., 2007, 2010). In contrast, recent evidence indicates that BDNF is increased after aerobic exercise but is not affected by resistance exercise in laboratory animals (Cassilhas et al., 2012). More information will be needed regarding the centrally mediated effects of resistance exercise in order to elucidate these putative biological mechanisms.

Under both single-bout and long-term training conditions, resistance exercise produces anxiolytic effects in a variety of populations. Future research will be necessary to translate these effects to a broader clinical environment; however, enough data exist to begin making recommendations for the design and implementation of resistance exercise-based treatments for anxiety disorders.

\section{AUTHOR CONTRIBUTIONS}

Both authors contributed to the literature search, initial draft of the manuscript, and revisions of the work. Both authors gave approval for the final version of the manuscript for submission and agree to be accountable for all aspects of the work.

\section{ACKNOWLEDGMENTS}

This work was supported by the NIH grants DA027485 and DA031725.

\section{REFERENCES}

Aberg, N. D., Brywe, K. G., and Isgaard, J. (2006). Aspects of growth hormone and insulin-like growth factor-1 related to nueroprotection, regeneration, and 
functional plasticity in the adult brain. ScientificWorldJournal 18, 53-80. doi: 10.1100/tsw.2006.22

Agil, A., Abike, F., Daskapan, A., Alaca, R., and Tuzun, H. (2010). Short-term exercise approaches on menopausal symptoms, psychological health, and quality of life in postmenopausal women. Obstet. Gynecol. Int. 2010, 7. doi: 10.1155/2010/ 274261

Aidar, F. J., de Oliveira, R. J., Silva, A. J., de Matos, D. G., Mazini Filho, M. L., Hickner, R. C., et al. (2012). The influence of resistance exercise training on the levels of anxiety in ischemic stroke. Stroke Res. Treat. 2012, 6. doi: 10.1155/2012/ 298375

American College of Sports Medicine. (2009). American college of sports medicine position stand. Progression models in resistance training for healthy adults. Med. Sci. Sports Exerc. 41, 687-708. doi: 10.1249/MSS.0b013e3181915670

Bartholomew, J. B., and Linder, D. E. (1998). State anxiety following resistance exercise: the role of gender and exercise intensity. J. Behav. Med. 21, 205-219. doi: 10.1023/A:1018732025340

Bibeau, W. S., Moore, J. B., Mitchell, N. G., Vargas-Tonsing, T., and Bartholomew J. B. (2010). Effects of acute resistance training of different intensities and rest periods on anxiety and affect. J. Strength Cond. Res. 24, 2184-2191. doi 10.1519/JSC.0b013e3181ae794b

Bircan, C., Karasel, S. A., Akgun, B., El, O., and Alper, S. (2008). Effects of muscle strengthening versus aerobic exercise program in fibromyalgia. Rheumatol. Int. 28, 527-532. doi: 10.1007/s00296-007-0484-5

Brogardh, C., and Lexell, J. (2012). Effects of cardiorespiratory fitness and muscleresistance training after stroke. $P M R$ 4, 901-907. doi: 10.1016/j.pmrj.2012. 09.1157

Cassilhas, R. C., Antunes, H. K., Tufik, S., and de Mello, M. T. (2010). Mood, anxiety, and serum IGF-1 in elderly men given 24 weeks of high resistance exercise. Percept Mot. Skills 110, 265-276. doi: 10.2466/PMS.110.1.265-276

Cassilhas, R. C., Lee, K. S., Fernandes, J., Oliveira, M. G. M., Tufik, S., Meeusen, R., et al. (2012). Spatial memory is improved by aerobic and resistance exercise through divergente molecular mechanisms. Neuroscience 202, 309-317. doi: 10.1016/j.neuroscience.2011.11.029

Cassilhas, R. C., Viana, V. A., Grassmann, V., Santos, R. T., Santos, R. F., Tufik S., et al. (2007). The impact of resistance exercise on the cognitive function of the elderly. Med. Sci. Sports Exerc. 39, 1401-1407. doi: 10.1249/mss.0b013e3180 $60111 \mathrm{f}$

Chrousos, G. P. (2009). Stress and disorders of the stress system. Nat. Rev. Endocrinol. 5, 374-381. doi: 10.1038/nrendo.2009.106

Courneya, K. S., Segal, R. J., Gelmon, K., Reid, R. D., Mackey, J. R., Friedenreich, C. M., et al. (2007a). Six-month follow-up of patient-rated outcomes in a randomized controlled trial of exercise training during breast cancer chemotherapy. Cancer Epidemiol. Biomarkers Prev. 16, 2572-2578. doi: 10.1158/1055-9965.EPI07-0413

Courneya, K. S., Segal, R. J., Mackey, J. R., Gelmon, K., Reid, R. D., Friedenreich, C. M., etal. (2007b). Effects of aerobic and resistance exercise in breast cancer patients receiving adjuvant chemotherapy: a multicenter randomized controlled trial. J. Clin. Oncol. 25, 4396-4404. doi: 10.1200/JCO.2006 08.2024

Crewther, B., Keogh, J., Cronin, J., and Cook, C. (2006). Possible stimuli for strength and power adaptation. Sports Med. 36, 215-238. doi: 10.2165/00007256200636030-00004

Crewther, B. T., Cook, C., Cardinale, M., Weatherby, R. P., and Lowe, T. (2011). Two emerging concepts for elite athletes: the short-term effects of testosterone and cortisol on the neuromuscular system and the dose-response training role of these endogenous hormones. Sports Med. 41, 103-123. doi: 10.2165/11539170000000000-00000

Endler, N. S., and Kocovski, N. L. (2001). State and trait anxiety revisited. J. Anxiety Disord. 15, 231-245. doi: 10.1016/S0887-6185(01)00060-3

Focht, B. C. (2002). Pre-exercise anxiety and the anxiolytic responses to acute bouts of self-selected and prescribed intensity resistance exercise. J. Sports Med. Phys. Fitness 42, 217-223.

Focht, B. C., and Koltyn, K. F. (1999). Influence of resistance exercise of different intensities on state anxiety and blood pressure. Med. Sci. Sports Exerc. 31, 456-463. doi: 10.1097/00005768-199903000-00016

Focht, B. C., and Koltyn, K. F. (2009). Alterations in pain perception after resistance exercise performed in the morning and evening. J. Strength Cond. Res. 23, 891897. doi: 10.1519/JSC.0b013e3181a05564
Garvin, A. W., Koltyn, K. F., and Morgan, W. P. (1997). Influence of acute physical activity and relaxation on state anxiety and blood lactate in untrained college males. Int. J. Sports Med. 18, 470-476. doi: 10.1055/s-2007-972666

Gomez-Pinilla, F., and Hillman, C. (2013). The influence of exercise on cognitive abilities. Compr. Physiol. 3, 403-428. doi: 10.1002/cphy.c110063

Herring, M. P., Jacob, M. L., Suveg, C., Dishman, R. K., and O'Connor, P. J. (2012). Feasibility of exercise training for the short-term treatment of generalized anxiety disorder: a randomized controlled trial. Psychother. Psychosom. 81, 21-28. doi: $10.1159 / 000327898$

Hillman, C. H., Pontifex, M. B., Raine, L. B., Castelli, D. M., Hall, E. E., and Kramer, A. F. (2009). The effect of acute treadmill walking on cognitive control and academic achievement in preadolescent children. Neuroscience 159, 10441054. doi: 10.1016/j.neuroscience.2009.01.057

Jette, A. M., Harris, B. A., Sleeper, L., Lachman, M. E., Heislein, D., Giorgetti, M., et al. (1996). A home-based exercise program for nondisabled older adults. J. Am. Geriatr. Soc. 44, 644-649.

Kessler, R. C., Petukhova, M., Sampson, N. A., Zaslavsky, A. M., and Wittchen, H. U. (2012). Twelve-month and lifetime prevalence and lifetime morbid risk of anxiety and mood disorders in the United States. Int. J. Methods Psychiatr. Res. 21, 169-184. doi: 10.1002/mpr.1359

Koltyn, K. F., and Arbogast, R. W. (1998). Perception of pain after resistance exercise. Br. J. Sports Med. 32, 20-24. doi: 10.1136/bjsm.32.1.20

Koltyn, K. F., Raglin, J. S., O’Connor, P. J., and Morgan, W. P. (1995). Influence of weight training on state anxiety, body awareness and blood pressure. Int. J. Sports Med. 16, 266-269. doi: 10.1055/s-2007-973003

Meewisse, M. L., Reitsma, J. B., de Vries, G. J., Gersons, B. P., and Olff, M. (2007). Cortisol and post-traumatic stress disorder in adults: systematic review and meta-analysis. Br. J. Psychiatry 191, 387-392. doi: 10.1192/bjp.bp.106. 024877

Norvell, N., and Belles, D. (1993). Psychological and physical benefits of circuit weight training in law enforcement personnel. J. Consult. Clin. Psychol. 61, 520527. doi: 10.1037/0022-006X.61.3.520

O’Connor, P. J., Bryant, C. X., Veltri, J. P., and Gebhardt, S. M. (1993). State anxiety and ambulatory blood pressure following resistance exercise in females. Med. Sci. Sports Exerc. 25, 516-521.

O'Connor, P. J., and Cook, D. B. (1998). Anxiety and systolic blood pressure reductions following acute exercise are not mediated by muscle contraction type. Int. J. Sports Med. 19, 188-192. doi: 10.1055/s-2007-971902

O'Connor, P. J., Herring, M. P., and Caravalho, A. (2010). Mental health benefits of strength training in adults. Am. J. Lifestyle Med. 4, 377-396. doi: $10.1177 / 1559827610368771$

Parker, A. G., Gordon, J., Thornton, A., Byars, A., Lubker, J., Bartlett, M., et al. (2011). The effects of IQPLUS Focus on cognitive function, mood and endocrine response before and following acute exercise. J. Int. Soc. Sports Nutr. 8:16. doi: 10.1186/1550-2783-8-16

Passos, G. S., Poyares, D., Santana, M. G., Garbuio, S. A., Tufik, S., and Mello, M. T. (2010). Effect of acute physical exercise on patients with chronic primary insomnia. J. Clin. Sleep Med. 6, 270-275.

Penedo, F. J., and Dahn, J. R. (2005). Exercise and well-being: a review of mental and physical health benefits associated with physical activity. Curr. Opin. Psychiatry 18, 189-193. doi: 10.1097/00001504-200503000-00013

Physical Activity Guidelines Advisory Committee. (2008). Physical activity guidelines advisory committee report, 2008. Washington: US Department of Health and Human Service.

Puetz, T. W., O'Connor, P. J., and Dishman, R. K. (2006). Effects of chronic exercise on feelings of energy and fatigue: a quantitative synthesis. Psychol. Bull. 132, 866-876. doi: 10.1037/0033-2909.132.6.866

Raglin, J. S., Turner, P. E., and Eksten, F. (1993). State anxiety and blood pressure following $30 \mathrm{~min}$ of leg ergometry or weight training. Med. Sci. Exerc. Sports 25, 1044-1048. doi: 10.1249/00005768-199309000-00012

Schoenborn, C. A., Adams, P. F., and Peregoy, J. A. (2013). Health Behaviors of Adults: United States, 2008-2010. National Center for Health Statistics. Vital Health Stat. 10.

Sjogren, T., Nissinen, K. J., Jarvenpaa, S. K., Ojanen, M. T., Vanharanta, H., and Malkia, E. A. (2006). Effects of a physical exercise intervention on subjective physical well-being, psychosocial functioning and general well-being among office workers: a cluster randomized-controlled cross-over design. Scand. J. Med. Sci. Sports 16, 381-390. doi: 10.1111/j.1600-0838.2005.00516.x 
Southwick, S. M., Vythilingam, M., and Charney, D. S. (2005). The psychobiology of depression and resilience to stress: implications for prevention and treatment. Annu. Rev. Clin. Psychol. 1, 255-291. doi: 10.1146/annurev.clinpsy. 1.102803 .143948

Spielberger, C. D. (1966). "Theory and research on anxiety," in Cross-Cultural Anxiety, eds C. D. Spielberger and R. Diaz-Guerrero (Washington: Hemisphere), $3-10$.

Spielberger, C. D. (1983). Manual for the State-Trait Anxiety Inventory: STAI (Form Y). Palo Alto, CA: Consulting Psychologists Press.

Tsutsumi, T., Don, B. M., Zaichkowsky, L. D., and Delizonna, L. L. (1997). Physical fitness and psychological benefits of strength training in community dwelling older adults. Appl. Human Sci. 16, 257-266. doi: 10.2114/jpa.16.257

Tsutsumi, T., Don, B. M., Zaichkowsky, L. D., Takenaka, K., Oka, K., and Ohno, T. (1998). Comparison of high and moderate intensity of strength training on mood and anxiety in older adults. Percept. Motor Skills 87, 1003-1011. doi: 10.2466/pms.1998.87.3.1003
Conflict of Interest Statement: The authors declare that the research was conducted in the absence of any commercial or financial relationships that could be construed as a potential conflict of interest.

Received: 23 April 2014; accepted: 27 June 2014; published online: 10 July 2014.

Citation: Strickland JC and Smith MA (2014) The anxiolytic effects of resistance exercise. Front. Psychol. 5:753. doi: 10.3389/fpsyg.2014.00753

This article was submitted to Movement Science and Sport Psychology, a section of the journal Frontiers in Psychology.

Copyright (c) 2014 Strickland and Smith. This is an open-access article distributed under the terms of the Creative Commons Attribution License (CC BY). The use, distribution or reproduction in other forums is permitted, provided the original author(s) or licensor are credited and that the original publication in this journal is cited, in accordance with accepted academic practice. No use, distribution or reproduction is permitted which does not comply with these terms. 